\title{
Modeling Conductive Cooling for Thermally Stressed Dairy Cows
}

\author{
Kifle G. Gebremedhin ${ }^{1}$, Binxin $\mathrm{Wu}^{1}$ and K. Perano ${ }^{1}$
}

\section{ABSTRACT}

Conductive cooling, which is based on direct contact between a cow lying down and a cooled surface (water mattress, or any other heat exchanger embedded under the bedding), allows heat transfer from the cow to the cooled surface, and thus alleviate heat stress of the cow. Conductive cooling is a novel technology that has the potential to reduce the consumption of energy and water in cooling dairy cows compared to some current practices. A three-dimensional conduction model that simulates cooling thermally-stressed dairy cows was developed. The model used a computational fluid dynamics (CFD) method to characterize the air-flow field surrounding the animal model. The flow field was obtained by solving the continuity and the momentum equations. The heat exchange between the animal and the cooled water mattress as well as between the animal and ambient air was determined by solving the energy equation. The relative humidity was characterized using the species transport equation. The conduction 3-D model was validated against experimental temperature data and the agreement was very good (average error is $4.4 \%$ and the range is 1.9-8.3\%) for a mesh size of 1117202. Sensitivity analyses were conducted between heat losses (sensible and latent) with respect to air temperature, relative humidity, air velocity, and level of wetness of skin surface to determine which of the parameters affect heat flux more than others. Heat flux was more sensitive to air temperature and level of wetness of the skin surface and less sensitive to relative humidity.

Keywords: Conductive Cooling, Heat Stress, Dairy Cows, CFD Model, Heat Flux.

\subsection{INTRODUCTION}

Dairy cows regulate their body temperature to maintain a metabolically favorable temperature. Cows generate heat from metabolism and from physical activity including thermoregulatory mechanisms such as increased respiration, physiological activities such as lactation lead to increased metabolic heat production and thus increased need to dispose of body heat. The variation in core-body temperature (the mean temperature of an animal's deep-body tissues) should be kept

${ }^{1}$ Professor, Senior Research Associate and Ph.D. Student, Department of Biological and Environmental Engineering, Cornell University, Ithaca, NY 14853. 
within a very narrow margin in order for the animal to stay within the zone of least

32 thermoregulation. Otherwise, when the body temperature of the cow gets too high, heat stress will set in (Mondaca, et al., 2013). Even a $0.5^{0} \mathrm{C}$ change in core-body temperature will negatively affect a cow's performance (Allen et al., 2013). West (2003) reported that failure to maintain 35 homeostasis at temperatures beyond the cow's thermo-neutral zone (or zone of least thermoregulation) will result in decreased milk production, reduced fertility, increased water consumption, reduced feed intake, more time spent standing (and fewer resting hours), and increased lameness. Extreme heat stress may lead to abortions or even death (West, 2003). In economic terms, the loss to the U.S. dairy industry due to thermal stress is about one billion dollars per year (St-Pierre et al, 2003). This loss does not take into account what might happen in the face of climate change, higher energy costs, or more water scarcity.

Current practices used to alleviate heat stress of cows include the following: forced convection and evaporative cooling systems that may include fans and misters or sprinklers, feed-line soakers, cross-ventilation, and evaporative cooling units such as Korral Kool. These systems increase heat transfer by evaporation and convection and decrease the temperature of the air surrounding the animal as well as the skin surface temperature. However, these systems will not be as effective under hot and humid conditions because of reduced moisture gradient between the skin surface and ambient air. Some of these systems also require a significant amount of water and electricity. Conductive cooling is an alternative method of cooling dairy cows that will work just as effectively under humid conditions and could also be complementary to existing systems.

Conductive cooling, which is based on direct contact between a cow lying down and a cooled 54 surface (water mattress, or any other heat exchanger embedded under the bedding), allows heat transfer from the cow to the cooled surface, and thus alleviates some of the heat stress of the cow.

56 Conductive cooling has the potential to conserve water (by recycling all the water as a working 57 fluid in a closed-loop system) and may require less energy than evaporative cooling units such as Korral Kool. Conductive cooling may also improve animal hygiene and reduce humidity in the barn compared to evaporative cooling systems. 
Animal cooling by conduction is a fairly new concept. There are only a few studies in the literature on the subject. To our knowledge, three universities (Cornell University, the University of Arizona and the University of Wisconsin-Madison) have been involved in conductive cooling of dairy cows using some sort of heat exchangers. The references associated with the studies in these universities are discussed below.

The pioneering study in conductive cooling, which consisted of both experimental work and modeling was done by Bastian et.al. (2003). The experimental component of the study involved measurement of heat flux that cows lose to waterbeds when they lie down on them. The temperature of the surface (rubber) where the cows lied down was cooler than the skin surface temperature, thus the animals lost heat to the water inside the waterbed. During the experiment, the water in the waterbed was static and was not cooled. The modeling component involved a finite difference model that predicted heat flow from the cow to the waterbed. In the model simulation, the water in the waterbed was cooled to $10^{\circ} \mathrm{C}$, and consequently a cow lying down on the cooled water mattress lost $400 \mathrm{~W}$ of heat by conduction. This amount of heat is equivalent to about $25 \%$ of an estimated 1,586 W of metabolic heat of a cow (Bastian et al., 2005). The study concluded that cows lying down on water mattresses can lose about $20-25 \%$ of their metabolic heat by conduction.

Rojano et al. (2011) did a feasibility study of a dual cooling system for dairy cows. They proposed a conductive cooling system in which a heat exchanger placed under the bedding cools the animal while lying down. Subsequently, Mondeca et al. (2013) developed a computational fluid dynamics-based model that predicts heat loss of cows by conduction and performed sensitivity analysis to determine the effects of a range of parameters on conductive cooling. The focus of their study was on developing a conjugate heat and mass transfer 2-D model that considers physiological responses, hair-coat physical properties, and detailed interface boundary conditions. They solved a set of coupled, elliptic partial differential equations through discretization, and in which each control volume has a volumetric heat generation term. None of these two studies included experimental studies with live animals, and thus the models were not fully validated. Both studies concluded that conductive cooling could alleviate heat stress of cows during hot and humid weather. 
93 Perano et al. (2015a) conducted extensive experimental and empirical studies to determine the 94 effectiveness of conductive cooling in alleviating heat stress of dairy cows. The experimental 95 work involved exposing dairy cows to hot and humid conditions and conductively cooling half of 96 the cows by providing cooled water mattresses for them to lie on. The circulating water in the 97 water mattress was cooled to $4.5^{\circ} \mathrm{C}$ or $10^{\circ} \mathrm{C}$. When the cows were cooled at $4.5^{0} \mathrm{C}$ water temperature, they produced up to $11 \%$ more milk than the control group that were exposed to the same environmental conditions but not cooled. The core-body temperature and respiration rate of the cooled cows were up to $1.1^{\circ} \mathrm{C}$ and 22 breaths/min, respectively, lower than the control cows.

101

102 103 This study conclusively demonstrated that conductive cooling can be an effective cooling mechanism for heat-stressed dairy cows.

Lately, Ortiz et al. (2015) experimentally evaluated the effectiveness of conductive cooling of dairy cows with heat exchangers buried under $25-\mathrm{cm}$ of bedding. They justified the deep bedding to protect the heat exchanger and keep the cows comfortable. The water in the heat exchanger was cooled to $7^{\circ} \mathrm{C}$ and sand or dried manure were used as bedding materials. They reported that there was no difference in respiration rate between the cooled and the not cooled cows but the core-body temperature was decreased by $0.13^{\circ} \mathrm{C}$ when sand was used as bedding and by $0.14^{0} \mathrm{C}$ when dried manure was used as bedding. They also reported low value of conductive heat flux $\left(28.63 \mathrm{~W} / \mathrm{m}^{2}\right.$ when sand was used as bedding and $7.35 \mathrm{~W} / \mathrm{m}^{2}$ when manure was used as bedding). These low values of heat flux could be due to the use of deep bedding $(25 \mathrm{~cm})$ in the study. They concluded that more work needs to be done to determine the efficacy of conductive cooling.

Based on our literature search, we did not find a fundamentally-based model that predicts conductive heat flow from a cow lying down on a cooled heat exchanger. A fundamentally-based model would provide insight in terms of how much heat of metabolism can be lost by conduction versus by evaporation and radiation, and such a model would enable parametric studies to identify the most sensitive variables to affect heat loss.

\subsection{Objectives}


123 The overall objective of this study was to simulate heat exchange between a cow and her 124 surrounding environment (ambient air and water mattress) using computational fluid dynamics 125 (CFD) technique. The specific objectives were to:

126 1. Develop a CFD model that characterizes airflow, heat transfer, and relative humidity within a 127 space occupied by a cow.

128

129

2. Develop a 3-D mathematical model that simulates heat flow by conduction from a cow to a cooled water mattress (heat exchanger) when the cow was laying down.

3. Validate the predictions of the conduction model against measured surface temperature at the interface of a cow laying down and the water mattress.

4. Conduct sensitivity analyses of heat flow with respect to changes in ambient air temperature, relative humidity, air velocity and level of wetness of the skin surface.

\section{MODEL DEVELOPMENT}

\subsection{Assumptions}

1. Air flow surrounding the cow model was laminar.

2. Air flow and heat transfer were steady state.

3. Cutaneous evaporation occurred only from the skin surface exposed to ambient air.

4. Metabolic heat production was estimated to be $1855 \mathrm{~W}$ for a $682-\mathrm{kg}$ cow producing $55 \mathrm{~kg} / \mathrm{day}$ of milk.

5. Thickness of skin was $5 \mathrm{~mm}$ and its thermal resistance was $0.039 \mathrm{~m}^{2}-\mathrm{K} / \mathrm{W}$ (McArthur, 1981)

6. The length of the cow model was $2.15 \mathrm{~m}$ and the contact area was $1 \mathrm{~m}^{2}$.

7. The space occupied by the model cow was $4 \mathrm{~m}$-length $\times 4 \mathrm{~m}$-width $\times 1 \mathrm{~m}$-height.

8. Hair density was 26 hairs $/ \mathrm{cm}^{2}$ and the thickness of the hair coat was $12 \mathrm{~mm}$ but the compressed thickness of the hair coat (in contact with the water mattress) was $1 \mathrm{~mm}$.

9. Heat loss by respiration was not included in this study.

\subsection{Model Formulation}

Based on the above assumptions and Fig.1, the governing equations used to characterize the airflow field pattern surrounding the animal were the continuity and momentum equations (Eqs. 1 and 2), the governing equation used to determine the heat transfer between the contact area of the body of the cow and the water mattress as well as the heat transfer between the cow and ambient 
154 air was the energy equation (Eq. 3), and the equation used to characterize the relative humidity

155 was the species transport equation (Eq. 5). These equations are given below.

\section{2.3. Continuity equation}

158 The continuity equation used to determine the air flow pattern is expressed as

$159 \quad \frac{\partial \rho}{\partial t}+\nabla \cdot(\rho \vec{u})=S_{m}$

where, $\rho$ is air density, $\mathrm{t}$ is time, $\overrightarrow{\boldsymbol{u}}$ is velocity vector, and $\mathrm{S}_{\mathrm{m}}$ is the source term of mass.

\subsection{Momentum equation}

163 The momentum equations used to determine the air flow pattern is expressed as (Patankar, 1980)

$164 \frac{\partial}{\partial t}(\rho \phi)+\operatorname{div}(\rho \vec{u} \phi)=\operatorname{div}\left(\Gamma_{\phi} \nabla \phi\right)+S_{\phi}$

165 where $\phi$ represents velocity component, $\Gamma_{\phi}$ is the transport coefficient, and $S_{\phi}$ is the source term, 166 which is dependent on $\phi$.

167

168

\subsection{Energy equation}

169 The energy equation used to determine the heat exchange between the cow and its surrounding is 170 expressed as (ANSYS-Fluent Inc., 2013)

$171 \quad \frac{\partial}{\partial t}(\rho E)+\nabla \cdot(\vec{u}(\rho E+p))=\nabla \cdot\left(k_{e f f} \nabla T-\sum_{j} h_{j} \vec{J}_{j}+\left(\overline{\bar{\tau}}_{e f f} \cdot \vec{u}\right)\right)+S_{h}$

172 where, $\mathrm{p}$ is pressure, $\mathrm{T}$ is temperature, $\mathrm{k}_{\mathrm{eff}}$ is effective thermal conductivity, $\mathrm{h}_{\mathrm{j}}$ is enthalpy of species

$173 \mathrm{j}, \vec{J}_{j}$ is diffusion flux of species $\mathrm{j}, \overline{\bar{\tau}}_{\text {eff }}$ is viscous stress, and $\mathrm{S}_{\mathrm{h}}$ is heat source due to metabolic 174 heat production.

175 In equation (3), $\mathrm{E}$ is expressed as

$176 E=h-\frac{p}{\rho}+\frac{v^{2}}{2}$

177 where, $\mathrm{h}$ is enthalpy and $\mathrm{v}$ is velocity.

178

179

\subsection{Species transport equation}


180 The species transport equation used to characterize relative humidity is expressed as (ANSYS-

181 Fluent Inc., 2013)

$\frac{\partial}{\partial t}\left(\rho Y_{i}\right)+\Delta \cdot\left(\rho \vec{u} Y_{i}\right)=-\nabla \cdot \vec{J}_{i}+R_{i}+S_{i}$

183 where, $\mathrm{Y}_{\mathrm{i}}$ is mass fraction of each species, $\vec{J}_{i}$ is diffusion flux of species $i, \mathrm{R}_{\mathrm{i}}$ is net rate of 184 production of species $\mathrm{i}$ by chemical reaction, and $\mathrm{S}_{\mathrm{i}}$ is the source term.

185

186

\subsection{Water evaporation model}

187 The heat transfer by evaporation, convective and radiation were modeled assuming 1-D flow. The 188 interaction among these three pathways is through skin temperature, as shown in the formulation given below.

190

191 The latent heat loss, qevap, (W) due to water evaporating from the skin surface was calculated using 192 the model developed by Gebremedhin and Wu (2001), which was based on Fick's law, and is 193 expressed as

$194 Q_{\text {evap }}=\lambda j " \beta A_{s}$

195 where, $\lambda$ is the latent heat of vaporization of water at the temperature of the skin surface $(\mathrm{kJ} / \mathrm{kg}), \beta$

196 is percent of skin surface that is wet, and $\mathrm{j}$ " is total mass flux of water vapor that evaporates from 197 the skin surface $\left(\mathrm{kg} / \mathrm{m}^{2} \mathrm{~s}\right)$.

198

199 The flux of water that evaporates from the skin surface was calculated as

$200 \quad j^{\prime \prime}=\left(C_{\text {skin }}-C_{0}\right) /\left(\frac{1}{h_{m}}+\frac{\delta_{1}+\delta_{2}}{D}\right)$

201 where, $\mathrm{C}_{\text {skin }}$ is the concentration of water vapor $\left(\mathrm{kg} / \mathrm{m}^{3}\right)$ at the skin surface which is a function of 202 skin temperature $\left(\mathrm{T}_{\text {skin }}\right), \mathrm{C}_{0}$ is the concentration of water vapor $\left(\mathrm{kg} / \mathrm{m}^{3}\right)$ of ambient air, $\mathrm{h}_{\mathrm{m}}$ is 203 convective mass transfer coefficient $(\mathrm{m} / \mathrm{s}), \delta_{1}$ is thickness of the hair coat $(\mathrm{m}), \delta_{2}$ is thickness of a 204 thin film of air layer above the hair coat (m), and D is mass diffusion coefficient of water vapor $205\left(\mathrm{~m}^{2} / \mathrm{s}\right)$.

206

\subsection{Convective heat transfer model}


208 The convective heat flow, $\mathrm{Q}_{\text {conv }}$, (W) from the skin surface to ambient air was calculated as

209 (Gebremedhin and $\mathrm{Wu}, 2001)$

$210 Q_{\text {conv }}=q_{c}^{\prime \prime} A_{s}$

211 where, ${ }^{\mathrm{\prime}}{ }_{\mathrm{c}}$ is convective heat flux $\left(\mathrm{W} / \mathrm{m}^{2}\right)$ calculated as

$212 \quad q_{c}^{\prime \prime}=\frac{T_{\text {skin }}-T_{a}}{1 / h_{c}+\delta_{1} / k_{e f f}+\delta_{2} / k_{\text {air }}}$

213 where, $\mathrm{T}_{\mathrm{a}}$ is ambient air temperature $(\mathrm{K}), \mathrm{h}_{\mathrm{c}}$ is convective heat transfer coefficient $\left(\mathrm{W} / \mathrm{m}^{2}-\mathrm{K}\right)$

214 calculated according to Gebremedhin and $\mathrm{Wu}$ (2001), $\mathrm{k}_{\mathrm{eff}}$ is effective thermal conductivity of the

215 hair coat $(\mathrm{W} / \mathrm{m}-\mathrm{K})$, and $\mathrm{k}_{\mathrm{air}}$ is thermal conductivity of air $(\mathrm{W} / \mathrm{m}-\mathrm{K})$.

216

\section{2.9. Radiant heat transfer model}

218 The radiant heat exchange, $\mathrm{Q}_{\mathrm{rad}},(\mathrm{W})$ between the body of the cow and its surroundings was 219 calculated as (Gebremedhin and $\mathrm{Wu}, 2002)$

$220 Q_{\text {rad }}=q_{r}^{\prime \prime} A_{s}$

221 where, ${ }^{\mathrm{q}}{ }_{\mathrm{r}}$ is radiant heat flux $\left(\mathrm{W} / \mathrm{m}^{2}\right)$ calculated as

$222 q_{r}=\varepsilon f_{\text {fur }} f_{\text {eff }} h_{r}\left(T_{\text {skin }}-T_{m r t}\right)$

223 where, $\varepsilon$ is radiant emissive coefficient of a cow's skin, $f_{\text {fur }}$ is ratio of fur surface area to skin

224 surface area, $\mathrm{f}_{\text {eff }}$ is coefficient of effective radiant area, $\mathrm{h}_{\mathrm{r}}$ is coefficient of radiant heat transfer, and

$225 \mathrm{~T}_{\mathrm{mrt}}$ is mean radiant temperature assumed to be ambient temperature.

226

227

\subsection{Computational domain}

228 A cow lying down was represented by a truncated cylinder oriented perpendicular to an incoming 229 wind (Fig. 2). The simplified geometry of the cow laying down consists of four surfaces (Fig. 2).

$230 \mathrm{~S}_{1}$ representing the skin surface of the cow in contact with the water mattress assumed to be $1 \mathrm{~m}^{2}$,

$231 S_{2}$ representing the two ends, and $S_{3}$ representing the areas of the skin surface in contact with 232 ambient air. By solving Equations 12 through 18, the radius of the cylinder (r) and the height of 233 the arc (h) can be calculated, and thus define the computational domain.

234

235

\subsection{Determination of arc height of the cow model}


236 Assuming the length of a cow $(2.15 \mathrm{~m})$ and the contact area $\left(1 \mathrm{~m}^{2}\right)$ between the cow and the water

237 mattress, the arc height, h, shown in Fig. 2, was determined.

238 The surface area of a cow, As, can be estimated from body weight as (Brody, 1945)

$239 A_{S}=0.15 W^{0.56}$

240 where, $\mathrm{W}$ is body weight $(\mathrm{kg})$.

241 The width of the arc can be calculated as

$2422 a=S_{1} / L$

243 where, $S_{1}$ is contact area between the cow and the water mattress, $L$ is length of the cow and $a$ is

244 the width of the arc (Fig. 2).

245 The length of the arc, $1_{\mathrm{s}}$, of $\mathrm{S}_{2}$ was calculated as

$246 \quad l_{s}=2 \pi r-\frac{2 \pi r}{180} \operatorname{arctg} \frac{a}{\sqrt{r^{2}-a^{2}}}$

247 The end surface area, $\mathrm{S}_{2}$, was calculated as

248

$S_{2}=\pi r^{2}-\left[r\left(\frac{2 \pi r}{180} \operatorname{arctg} \frac{a}{\sqrt{r^{2}-a^{2}}}-2 a\right)+2 a\left(r-\sqrt{r^{2}-a^{2}}\right)\right] / 2$

249 The surface area, $S_{3}$, was calculated as

$250 \quad S_{3}=l_{s} L$

251 The radius of the "cow", r, can be solved by substituting Eqs. (12-15) into Eq. (17) as

$252 \quad A_{S}=S_{1}+2 S_{2}+S_{3}$

253 The arc height, h, was calculated as

$254 h=r+\sqrt{r^{2}-a^{2}}$

255

256 2.12. Calculation of Reynolds number

257 The hydraulic diameter was calculated as

$258 \quad D_{h}=\frac{4 S_{2}}{l_{s}+2 a}$

259 Given $D_{h}$, the Reynold number can be calculated as

$260 \quad \operatorname{Re}=\frac{\rho v_{i n} D_{h}}{\mu}$ 
where, $v_{\text {in }}$ is inlet velocity and $\mu$ is dynamic viscosity of air.

\subsection{Physical and thermal properties required for the CFD model}

To perform simulation of air flow around the animal model and heat exchange between the animal and its surroundings, the physical and/or thermal properties of the water mattress, air, water, hair coat, and skin need to be defined. The physical properties of air and water and the thermal properties of the water mattress, hair coat and skin obtained from the literature (McArthur, 1981; Gebremedhin et al., 1981; Mondaca, et al., 2013) are given in Table 1. Thermal conductivity of the skin was calculated assuming 5-mm skin thickness and thermal resistance of $0.039 \mathrm{~m}^{2}-\mathrm{K} / \mathrm{W}$.

\subsection{Procedures for measurement of interface temperature}

272 The model temperature prediction was validated against data of temperature of the interface of

273 the rubber mat of the water mattress and the cow's skin when the cow was lying down. The data

274 was collected from live cows cooled with the same waterbeds as were simulated in the CFD model. The experimental cooling system set up is described in Perano et al. (2015b). The data was collected with thermocouples glued to the surface of the rubber mats. The thermocouple temperatures were measured and recorded every 2 minutes with a Campbell Scientific CR1000 data logger beginning 20 min after the cow laid down and continuing until the cow stood up (which ranged from 10 to 90 min of data collection). The thermocouples were installed on the beds of two of the cows. The measured interface temperature data were collected for 5 levels of water temperatures (ranging from $4.6-14.5^{\circ} \mathrm{C}$ ) for the circulated cooling water, and each water temperature level was supported by multiple lying events.

The interface temperatures were calculated with linear models, using water temperature level as a fixed effect and bed number and lying event nested within water temperature as random effects. The LSMs for the measured interface temperatures are given in Table 3. The water temperatures in Table 3 were also calculated with linear models and are the average inflow/outflow water temperature in the waterbed during the exact time the interface temperatures were taken. Ambient conditions during the measurements were $29.6^{\circ} \mathrm{C}, 57 \% \mathrm{RH}$, and an air velocity of $0.04 \mathrm{~m} / \mathrm{s}$. 
292 The convection coefficient $\left(h_{c}\right)$ was estimated from the Nusselt number to be $91 \mathrm{~W} / \mathrm{m}^{2}-\mathrm{K}$ at the

293 location on the waterbed where the rubber-skin interface temperature was measured (see Perano

294 et al., 2015b for the diagram of the waterbed geometry).

295

\subsection{CFD simulation}

297 The input values used for the simulation for the interface temperature were: Air temperature $=$ $29829.6^{0} \mathrm{C}$, relative humidity $=57 \%$ air velocity $=0.04 \mathrm{~m} / \mathrm{s}$, core temperature $=39{ }^{0} \mathrm{C}$, temperature 299 range of the water in the water mattress was between $4.6^{\circ} \mathrm{C}$ and $14.5^{\circ} \mathrm{C}$, which is the same as that 300 when the interface temperature was measured. The CFD simulation included grid generation and 301 iteratively solving the governing equations. Meshing the computational domain was done using 302 Gambit (ANSYS-Fluent Inc., 2013), and the governing equations were solved using Fluent 303 (ANSYS-Fluent Inc., 2013). The steps followed in solving the governing equations were: (1) solve 304 the continuity and momentum equations (Eqs. 1and 2, respectively) to obtain a fully converged 305 flow field, (2) solve the energy equation (Eq. 3) based on the flow field, (3) solve the species transport equation (Eq. 5) to obtain relative humidity based on the flow and temperature fields, and (4) perform post-processing. The calculations for heat exchange between the cow model and ambient air (Eqs. 6 through 11) was performed using our own developed code written in FORTRAN language.

\subsection{Mesh-independent test}

A numerical solution is sensitive to the number of mesh elements. The smaller the number of elements, the finer the mesh, and the higher the prediction accuracy. A fine mesh requires a longer computing time to obtain one solution. The principal purpose of mesh-independent test is to reach a compromise between computing time and prediction accuracy. In order to obtain an acceptable number of mesh elements, a mesh-independent test is usually performed by checking various mesh sizes and observing how the solution changes with respect to the mesh size. In this study, the meshindependent test was conducted simultaneously with model validation. Since heat flow from a cow to a water mattress primarily involves the skin surface, meshing the skin surface in contact with the water mattress becomes the point of interest. The mesh-independent test was done by changing the size of the face mesh of the skin surface while keeping the other mesh sizes unchanged. To generate a higher quality mesh, the whole computational domain was divided into a few sub- 
323 domains. Tetrahedral meshes were used for the zone that represents the cow body, while 324 hexahedral meshes were used for the other zones. In addition, size functions were used to control 325 the mesh growth.

\subsection{RESULTS AND DISCUSSION}

328

329

The mesh-independent test was performed to determine the error of the prediction associated with mesh size (Table 2). As shown in the table, the error reduced from $10 \%$ to $4 \%$ when the number of mesh elements was increased from 128678 to 1117202 . When the number of mesh elements were further increased to 1750846, the error was again reduced but at a much lower rate. Using a finer mesh did not seem to significantly improve the accuracy of the prediction but increased the computing time exponentially. For subsequent calculations, a mesh size of 1117202 and a face mesh size of $0.01 \mathrm{~m}$ were used.

The CFD model prediction of interface temperature was compared to measured temperature at a similar spot of live cows laying down on a water mattress (Table 3). As previously mentioned (Section 2.14), the inputs values for the environmental conditions in the simulation were identical to those under which the interface temperature measurements were made. On the average, the model predicted within $4.4 \%$ error (ranging from 1.9 to $8.3 \%$ ). We consider this result to be very good.

\subsection{Prediction of airflow}

The continuity and momentum equations (Eqs. 1 and 2, respectively) were solved first to obtain the airflow pattern around the animal model. The blue area in the velocity contour (Fig. 3a) represents low velocity while the red area represents high velocity. The velocity in the red area is greater than or equal to the maximum specified velocity, and the black area represents the model cow. In the entrance region, that is, between the air inlet and the cow model, the flow is relatively uniform because there is no obstruction to the flow path. When air flows through the narrow zone above the cow model, however, the flow accelerates due to reduced cross sectional area of the flow passage. As the flow passes the cow model, it slows down as it moves towards the outlet. The flow pattern is very complex in the leeward side, as shown by several blue and green areas. In addition to the global velocity contour (Fig. 3a), the velocity vector (Fig. 3b) and flow pathlines (Fiq. 3c) 
are given to better visualize the flow pattern within the space. Each pathline refers to a trace of a single particle in space. As shown in Fig. 3b, the motion of the particles of the fluid appear to be very orderly with all particles moving along a streamline from the inlet to the outlet, which is characteristic of a laminar flow, and consistent with our assumption.

\subsection{Prediction of heat flow}

After solving for the converged flow field (Section 3.1), the temperature profile from the internal core-body temperature to the water in the water mattress, and also from the core-body temperature to ambient air can be solved from the energy equation (Eq. 3). Figure 4 (a) shows the global view of the temperature profile through the cow model. As expected, the highest temperature is shown at the "internal cow body." To better visualize the temperature profile, two local profiles, (1) from the internal body (core) to the water in the water mattress, and (2) from the core to ambient, are shown in Figures 4(b) and 4(c), respectively.

Fig. 4(b) shows the temperature changing from red (high) at the core to blue (low) at the water mattress, as it should be. A similar trend is shown in Fig. 4(c). The temperature gradient between the core and the water is more uniform than that between the core and ambient because airflow affects the convective heat transfer at the hair coat-air boundary layer.

\subsection{Prediction of relative humidity}

Based on the flow and temperature fields, the species transport equation (Eq. 5) can be solved to predict relative humidity. Figure 5 shows the predicted results of relative humidity corresponding to the temperature profile shown in Fig. 4(a). Relative humidity is inversely proportional to temperature; that is, the higher the temperature, the lower the relative humidity. Thus, the relative humidity around the cow body, which is treated as a heat source, is lower than that in the space further away from the cow.

\subsection{Sensitivity analysis}

Sensitivity analyses were performed to determine the sensitivity of key parameters that affect heat flux/flow. Heat flux from the cow to the water mattress was simulated for five temperatures of the water in the mattress. These temperatures were: $4.6,6.9,10.8,12.7$, and $14.5^{\circ} \mathrm{C}$. The corresponding 
385

386

387

388

389

390

391

392

393

394

395

396

397

398

399

400

401

402

403

404

405

406

407

408

409

410

411

412

413

414

415

predicted heat fluxes were: $430,401,353,328$, and $306 \mathrm{~W} / \mathrm{m}^{2}$, respectively. The conductive heat flux decreased linearly with increasing cooling water temperature because the flux is dependent on the temperature gradient and convective heat transfer between the body of the cow and the cooling water in the water mattress.

Sensitivity of air temperature on skin temperature, convective, radiant and evaporative heat losses are given in Table 4. Because air temperature was lower than skin temperature, heat is lost from the skin surface. The lower the air temperature, the larger the temperature gradient from skin to air. For example, an increase in air temperature from 29.6 to $35^{\circ} \mathrm{C}$ increased the radiant heat loss much more than the convective and evaporative heat losses. This may be attributed to the fact that convective and evaporative heat losses are highly dependent on flow regimes (laminar or turbulent) whereas radiant heat transfer is a function of temperature gradient (Eq. 11).

Sensitivity of relative humidity on sensible and latent heat losses are given in Table 4. When relative humidity was increased from 57 to $80 \%$, the convective heat loss remained unchanged because air velocity was constant. The radiant heat loss also remained constant because the temperature gradient between the air and skin surface did not change much but the latent heat loss was affected negatively. Increasing relative humidity decreases the vapor concentration gradient between the skin surface and ambient air and thus reduces the evaporative heat loss. A decrease in evaporative cooling resulted in an increase of skin surface temperature, which in turn increased the sensible heat loss. The overall effect of increasing relative humidity was to decrease the total heat loss from the animal.

Sensitivity of air velocity on the heat transfer mechanisms are given in Table 4. Generally, an increase in air velocity results in an increase of convective and evaporative heat losses and consequently reduces skin surface temperature. In this study, however, the influence of air velocity on sensible and latent heat losses was small because the air velocity considered was very low (0.04 $\mathrm{m} / \mathrm{s}$ ). Air velocity affects convective and evaporative heat losses considerably under turbulent flow conditions (Gebremedhin and $\mathrm{Wu}, 2003$ ). The Reynolds number calculated for the air velocity considered in this study was 1606, which is laminar. When the air velocity in this geometry exceeded $0.5 \mathrm{~m} / \mathrm{s}$, the flow becomes turbulent (Reynolds number = 20076). In this situation, an 
416 increase in air velocity increased convective and evaporative heat losses, and consequently reduced

417 the skin surface temperature. A lower temperature gradient between the skin surface and ambient

418 air decreased the radiant heat loss. The total heat loss increased with increasing air velocity because

419 the increase in convective and evaporative heat losses was much greater than the reduction in

420 radiative heat loss.

421

422 Sensitivity of level of skin wetness on the three heat transfer mechanisms is given in Table 4.

423 Increasing the level of wetness of the skin surface had no effect on the convective heat loss because

424 the convective heat transfer coefficient was constant because of constant air velocity. Radiation

425 was somewhat sensitive because of the cooling effect of evaporation on the skin. The effect of

426 level of wetness of the skin surface on evaporative heat loss was, however, significant. The greater

427 the level of wetness, the greater the evaporative heat loss and the greater the cooling effect.

428

429

430

The total heat loss (convection + radiation + evaporation + conduction) from the cow model was equal to $895 \mathrm{~W}$. This amount of heat loss was for the following environmental conditions: air velocity of $1.0 \mathrm{~m} / \mathrm{s}$, ambient air temperature of $29.6{ }^{\circ} \mathrm{C}$, relative humidity of $57 \%$ and level of skin

432 wetness of $60 \%$. If we assume a heat of metabolism of $1158 \mathrm{~W}$ for a $560-\mathrm{kg}$ cow, the total heat 433 loss $(895 \mathrm{~W})$ amounts to $77.3 \%$. The difference could be the heat loss by respiration.

\section{Conclusions}

1. The study develop a 3-D CFD model that predicts heat flow by conduction from a cow lying down on a cooled water mattress. The CFD model is capable of predicting the spatial distributions of airflow, temperature, and relative humidity in a space occupied by a cow. The method can be extended to study ventilated spaces with multiple occupants. The heat loss to ambient by convection, radiation and evaporation was modeled as 1-D flow.

2. The cooling performance of the water mattress was dependent on the temperature of the recirculating water inside the water mattress. The predicted heat flux for the $4.6^{\circ} \mathrm{C}$ cooling water temperature was $430 \mathrm{~W} / \mathrm{m}^{2}$ and dropped to $306 \mathrm{~W} / \mathrm{m}^{2}$ for a temperature of $14.5^{\circ} \mathrm{C}$. 
3. The predicted interface (cow skin - rubber mat interface) temperature from the 3-D conduction model was compared to experimentally measured temperature at a similar spot of a cow laying down on a water mattress for five temperatures of cooling water. On the average, the model predicted within $4.4 \%$ error (ranging from 1.9 to $8.3 \%$ ).

4. Sensitivity analyses showed that heat exchange between a cow and ambient air was sensitive to air temperature and level of skin wetness but less sensitive to relative humidity and laminar airflow.

\section{ACKNOWLEDGEMENTS}

This project was funded in part by New York State Energy Development Authority (NYSERDA) under agreement \#28264, and by the United States Department of Agriculture (USDA/ HATCH funds as part of the W-273 Regional Project through Cornell University.

\section{References}

1. Allen, J.D., S.D. Anderson, R.J. Collier, and J.F. Smith. 2013. Managing heat stress and its impact on cow behavior. In Proc. Western Dairy Mgmt. Conf., 150-162. Manhattan, Kansas, Kansas State University, Western dairy management Conference.

2. ANSYS. 2013. Fluent Users Guide 15.0. Lebanon, N.H.

3. Bastian, K.R., K.G. Gebremedhin, and N.R. Scott. 2003. Finite difference model to determine conduction heat loss to a water-filled mattress for dairy cows. Trans. ASAE 46(3): 773-780.

4. Brody, S. 1945. Bioenergetic and Growth. Reinhold Publishing Corporation, New York.

5. Gebremedhin, K.G., C.O. Cramer, and W.P. Porter. 1981. Predictions and measurements of heat production and food and water requirements of Holstein calves in different environments. Trans. ASAE 24(3):715-720.

6. Gebremedhin, K.G., and B. Wu. 2001. A model of evaporative cooling of wet skin surface and fur layer. Journal of Thermal Biology. 26(6): 537-545.

7. Gebremedhin, K.G., and B. Wu. 2002. Simulation of sensible and latent heat losses from wet-skin surface and fur layer. Journal of Thermal Biology. 27(4): 291-297. 
8. Gebremedhin, K.G., and B. Wu. 2003. Characterization of flow field in a ventilated space and simulation of heat exchange between cows and their environment. Journal of Thermal Biology. 28(2003): 301-319.

9. McArthur, A.J. 1981. Thermal resistance and sensible heat loss from animals. Journal of Thermal Biology. 6: 43-47.

10. Mondaca, M, F. Rojano, C.Y. Choi, and K.G. Gebremedhin. 2013. A conjugate heat and mass transfer model to evaluate the efficiency of conductive cooling for dairy cattle. Trans. ASABE. 56(6): 1471-1482.

11. Ortiz, X.A., J.F. Smith, F. Rojano, C.Y. Choi, J. Bruer, T. Steele, N. Schuring, J. Allen, and R.J. Collier. 2015. Evaluation of conductive cooling of lactating dairy cows under controlled environmental conditions. J. Dairy Sci. 98:1-13.

12. Patankar, S. V. 1980. Numerical Heat Transfer and Fluid Flow. New York, N.Y.: Hemisphere/McGraw Hill.

13. Perano, K. M., J. G. Usack, L. T. Angenent, K. G. Gebremedhin. 2015a. Production and physiological responses of heat-stressed lactating dairy cattle to conductive cooling. $\underline{J}$ Dairy Sci. 2015 Aug; 98(8):5252-61.

14. Perano, K.M., T.J. Shelford, and K.G. Gebremedhin. 2015b. Heat flux and condensation rate in conductive cooling systems for thermally stressed dairy cows. Proc. Dairy environmental systems and climate adaptation conference and tours. Cornell University, July 29-31, 2015. Biological and Environmental Engineering, Cornell University, Ithaca, NY.

15. Rojano, F., M. Mondaca, and C.Y. Choi. 2011. Feasibility of a dual cooling system for dairy cows in Arizona. ASABE Paper No. 1111661. St Joseph, MI, ASABE.

16. St-Pierre, N.R., B. Cobanov, and G. Schnitkey. 2003. Economic losses from heat stress by US livestock industries. J. Dairy Sci. 86:(E. Suppl.): E52-E77.

17. West, J.W. 2003. Effects of heat stress on production in dairy cattle. J. Dairy Sc. 86(6): 2131-2144. 


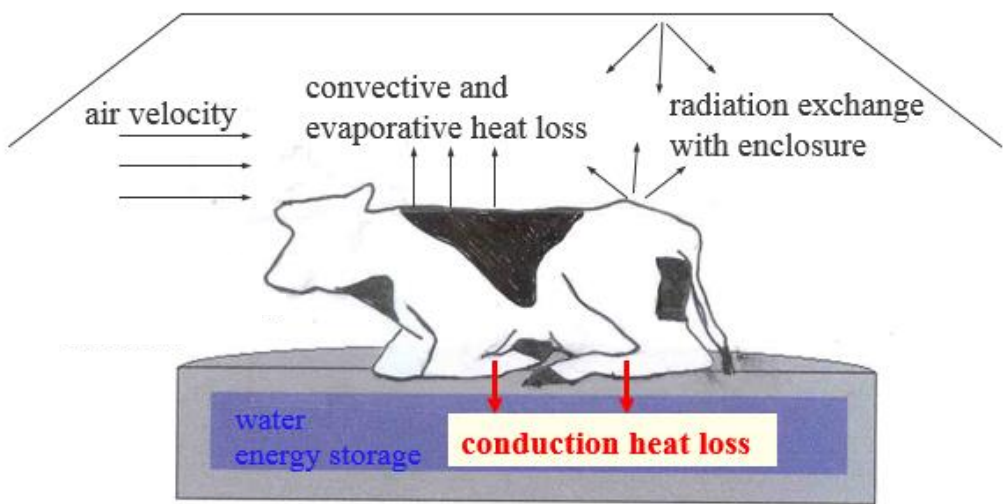

505 Fig.1. Diagram showing heat transfer components from cow body to its surrounding. The cow is 506 lying down on a cooled surface. 


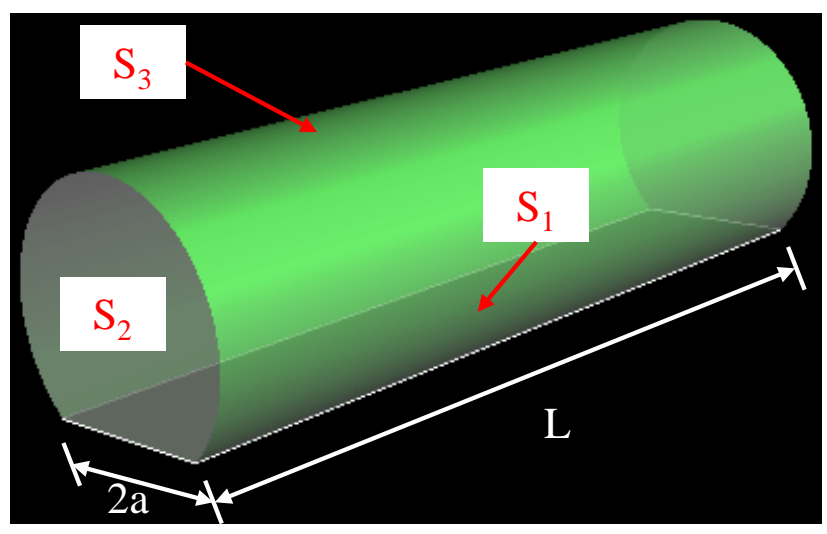

508

509

510

511

(a) 3-D view

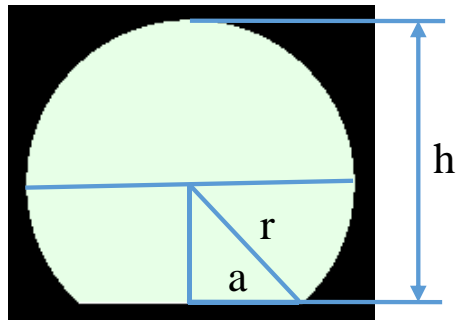

(b) 2-D view of cross section

Fig.2. A simplified geometry of cow body. 

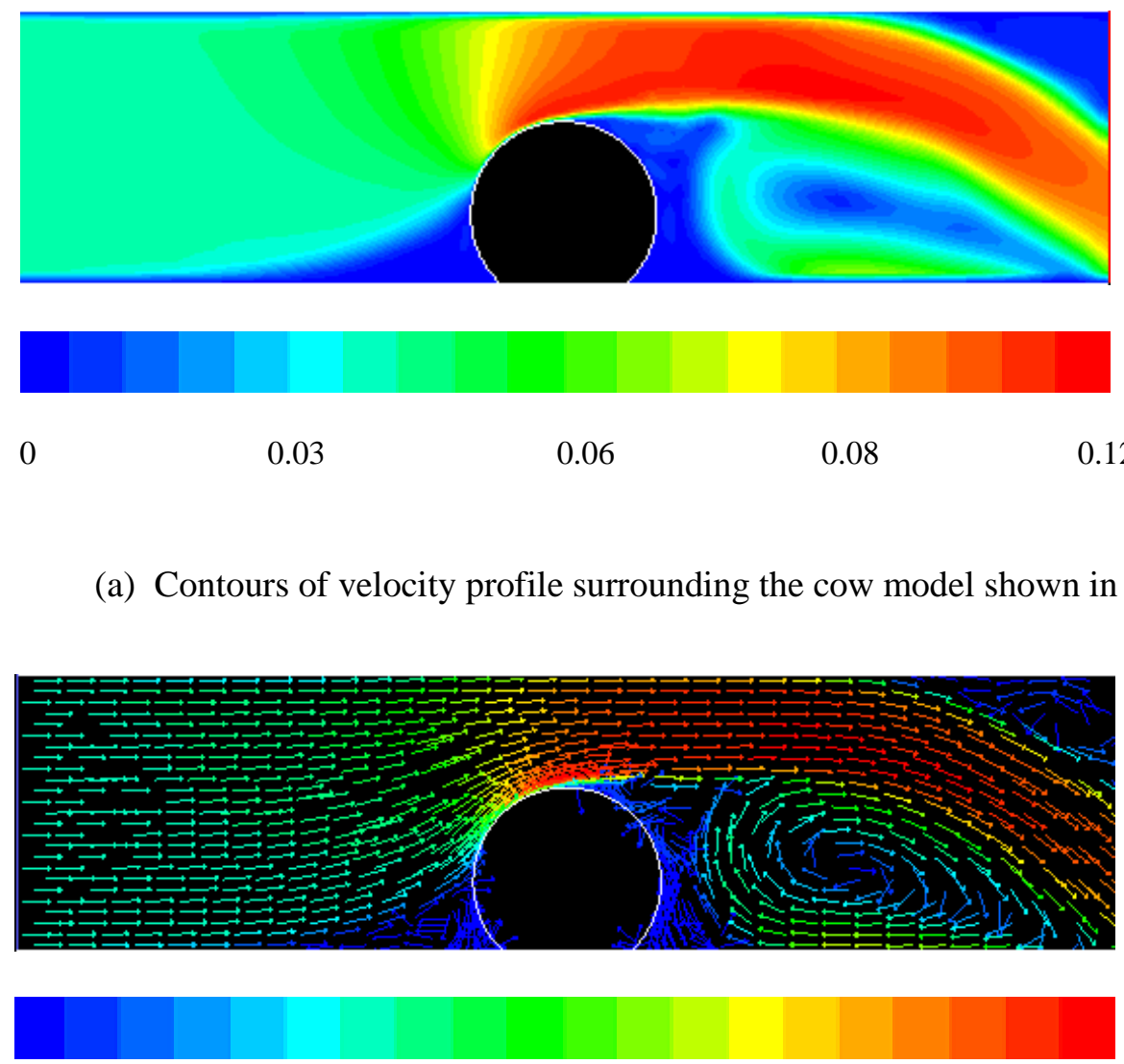

0

0.03

0.06

0.08

$0.12(\mathrm{~m} / \mathrm{s})$

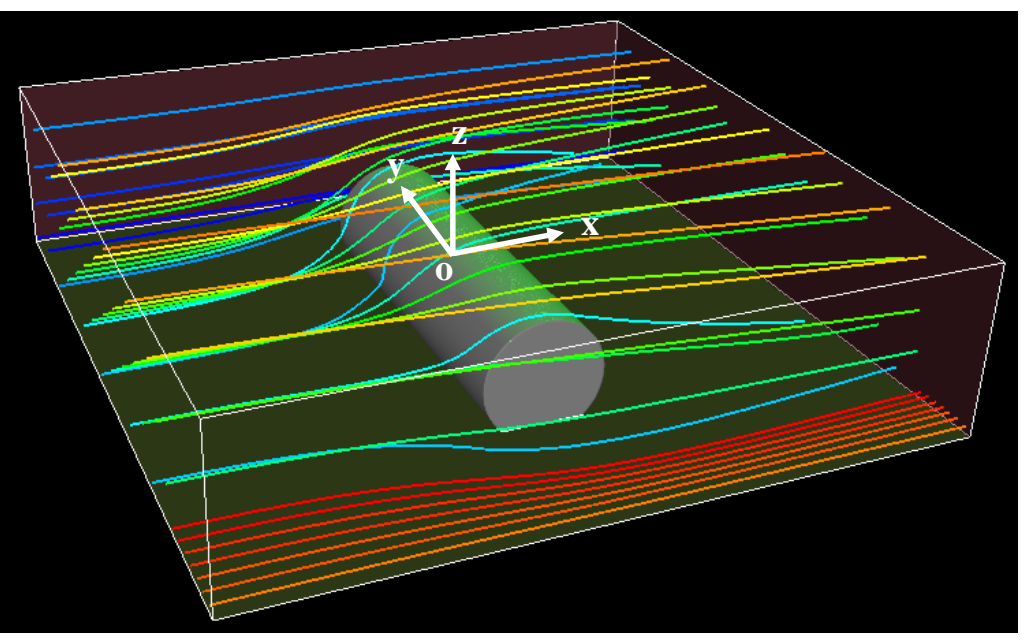

(c) Air flow pathlines colored by particles releasing from inlet.

518 Fig.3. Airflow pattern in the z-x plane at $y=0$ (based on the Cartesian coordinate system fixed at the center of the water mattress) 


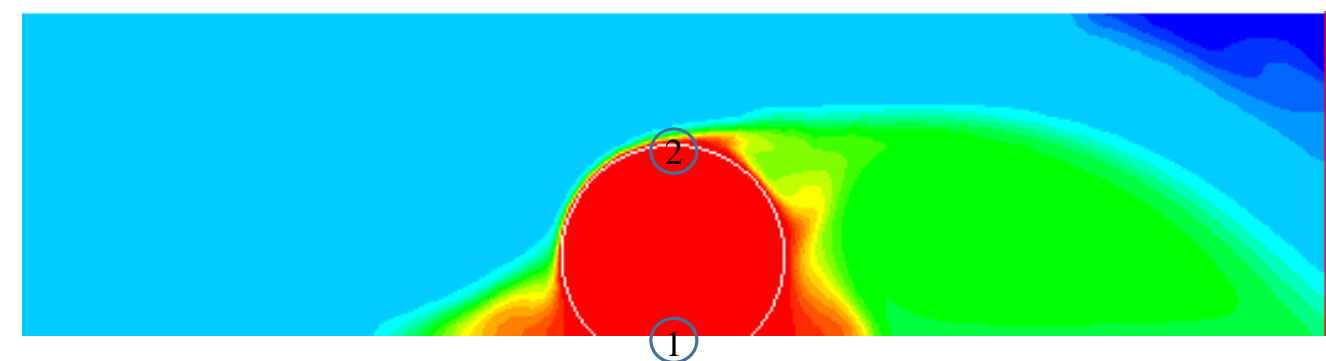

(a) Global view of temperature field surrounding the cow model.
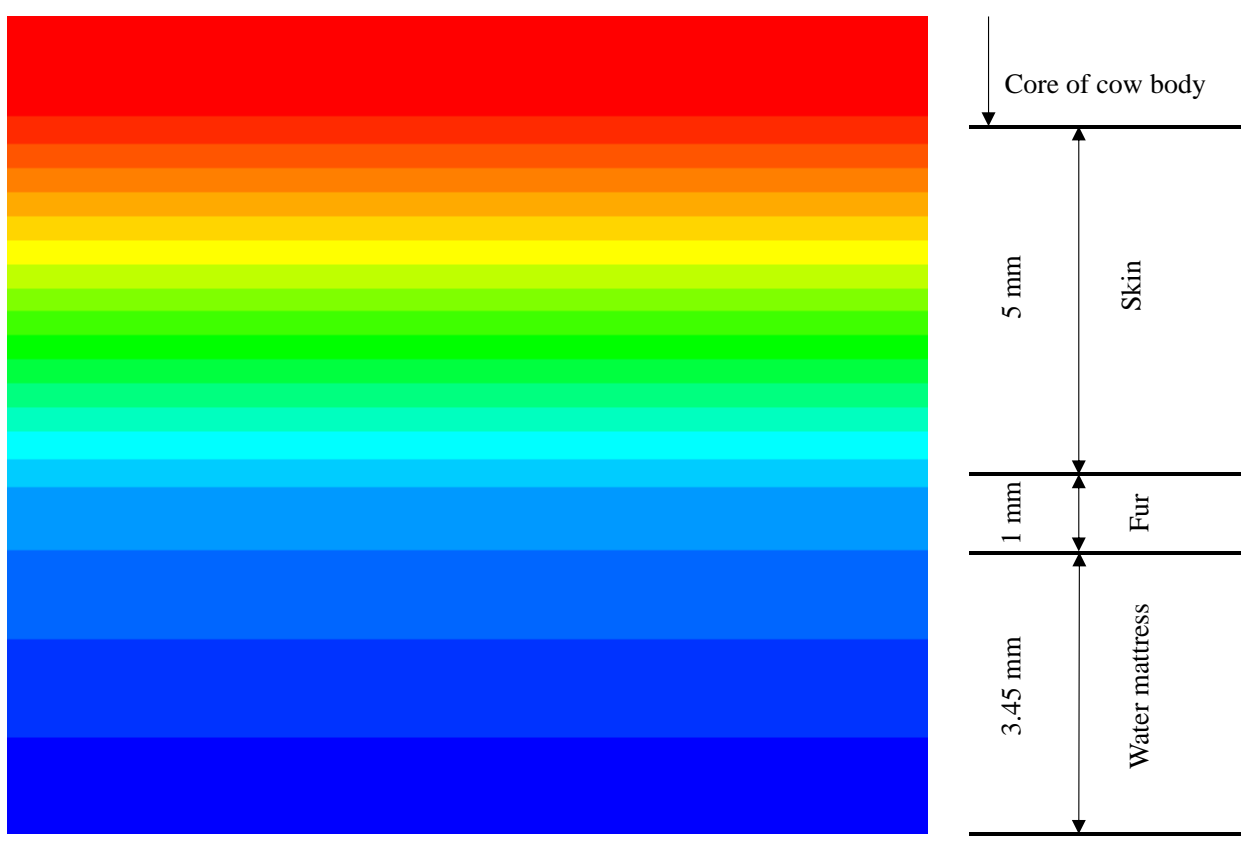

525 (b) Zoomed view of temperature profile for cow in contact with water mattress (Area 1 in a). 

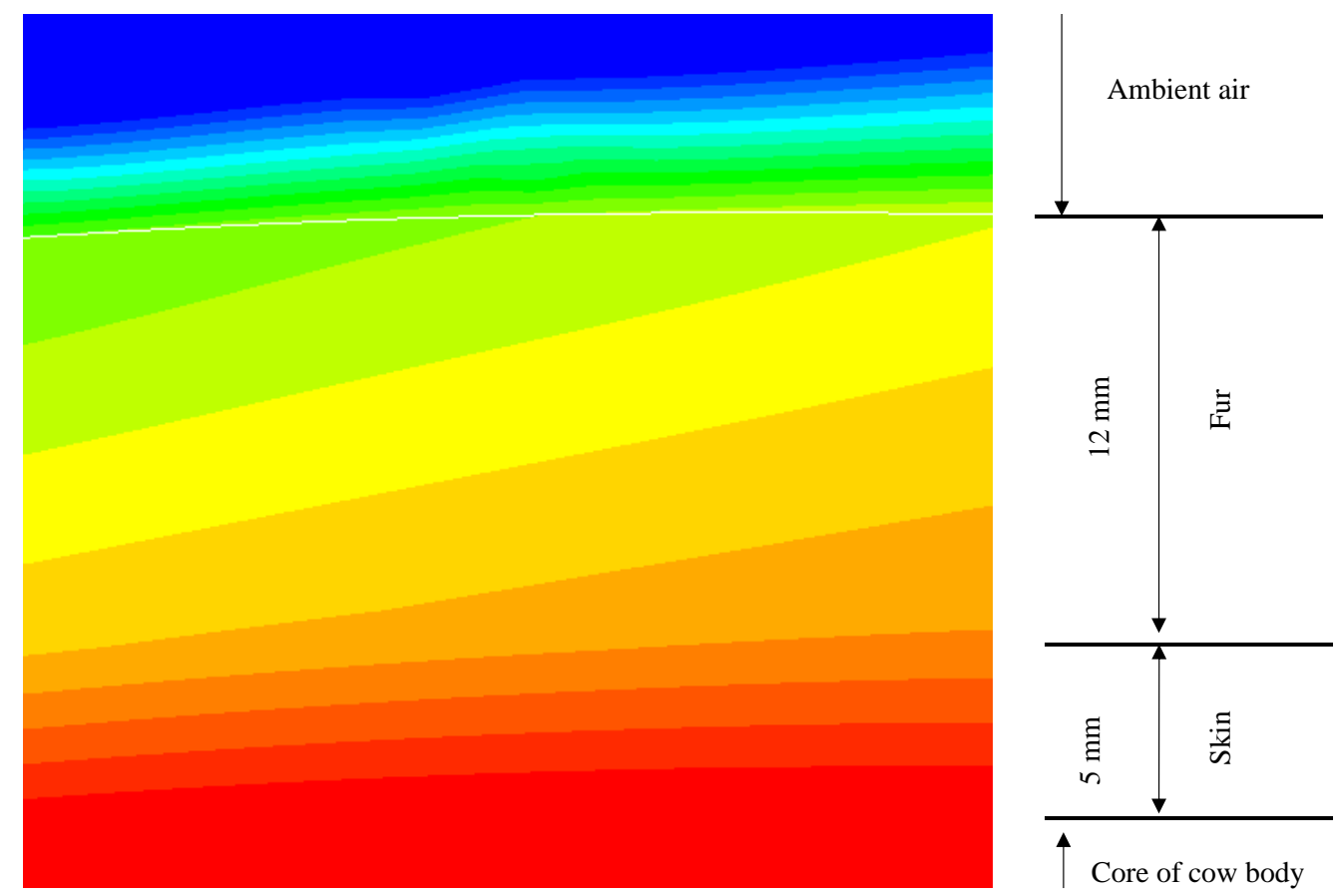

(c) Zoomed view of temperature profile for cow in contact with ambient air (Area 2 in a) 


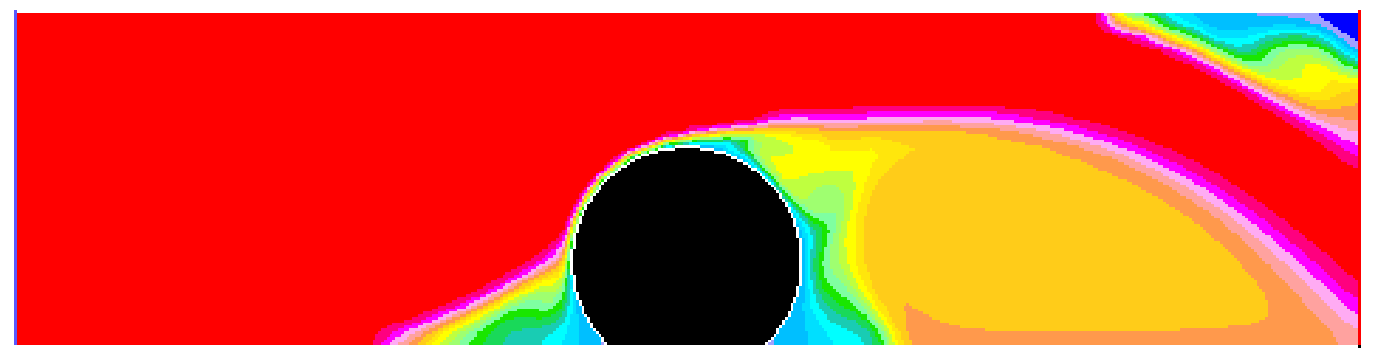

531

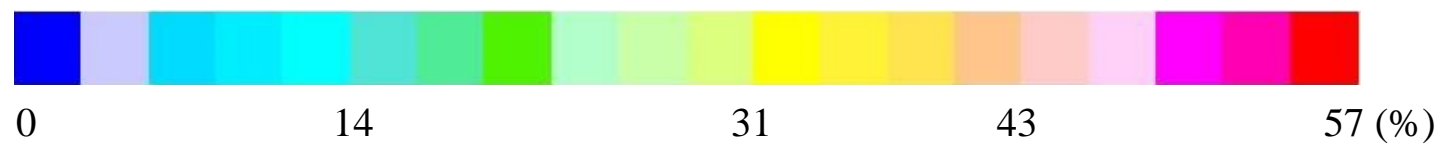

Fig.5. Contours of relative humidity surrounding the model cow shown in black.

533

534 
Table 1. Thermal and physical properties

\begin{tabular}{lcccccc}
\hline & Air & Water & Hair Coat & Skin & Tissue & $\begin{array}{c}\text { Water } \\
\text { Mattress }\end{array}$ \\
\hline Specific heat $(\mathrm{J} / \mathrm{kg}-\mathrm{K})$ & 1006.43 & 4182 & 1006.43 & 3472 & 3472 & 4182 \\
Thermal conductivity $(\mathrm{W} / \mathrm{m}-\mathrm{K})$ & 0.0242 & 0.6 & 0.26 & 0.1285 & 0.52 & 0.15 \\
Viscosity $(\mathrm{kg} / \mathrm{m}-\mathrm{s})$ & $1.7894 \times 10^{-5}$ & $1.003 \times 10^{-3}$ & & & & \\
Density $\left(\mathrm{kg} / \mathrm{m}^{3}\right)$ & 1.225 & 9982 & 998.2 & & & \\
\hline
\end{tabular}

535

536

537

538

539

540

541

542

Table 2. Grid-independent test based on a cooling water temperature of $4.6^{\circ} \mathrm{C}$.

\begin{tabular}{cccc}
\hline Mesh cells & $\begin{array}{c}\text { Measured } \\
\text { temperature } \\
\left({ }^{\circ} \mathrm{C}\right)\end{array}$ & $\begin{array}{c}\text { Predicted } \\
\text { temperature } \\
\left({ }^{\circ} \mathrm{C}\right)\end{array}$ & $\begin{array}{c}\text { Error } \\
(\%)\end{array}$ \\
\hline 128678 & 19.91 & 17.99 & $10 \%$ \\
283708 & 19.91 & 18.53 & $7 \%$ \\
1117202 & 19.91 & 19.14 & $4 \%$ \\
1396372 & 19.91 & 19.21 & $4 \%$ \\
1750846 & 19.91 & 19.25 & $3 \%$ \\
\hline
\end{tabular}

543 
547

548

549

Table 3. Comparison of the predicted and measured temperatures 551 at the top surface of the waterbed (where the cow lays down) for five temperatures of the cooling water .

\begin{tabular}{cccc}
\hline $\begin{array}{c}\text { Temperature of the } \\
\text { cooling water } \\
\left({ }^{\circ} \mathrm{C}\right)\end{array}$ & $\begin{array}{c}\text { Measured } \\
\text { temperature } \\
\left({ }^{\circ} \mathrm{C}\right)\end{array}$ & $\begin{array}{c}\text { Predicted } \\
\text { temperature } \\
\left({ }^{\circ} \mathrm{C}\right)\end{array}$ & $\begin{array}{c}\text { Error } \\
(\%)\end{array}$ \\
\hline 4.6 & 19.91 & 19.14 & $3.8 \%$ \\
6.9 & 20.09 & 20.48 & $1.9 \%$ \\
10.8 & 20.98 & 22.73 & $8.3 \%$ \\
12.7 & 23.04 & 23.81 & $3.3 \%$ \\
14.5 & 26.02 & 24.82 & $4.6 \%$ \\
\hline
\end{tabular}

552

553

554

555

556

557 
560 Table 4. Sensitivity analyses of air temperature, $T_{a}$, relative humidity $(R H)$, inlet air velocity, $v_{i n}$,

561 and level of skin wetness, $\beta$ on skin temperature, $T_{\text {skin, }}$ convective, $\mathrm{Q}_{\text {conv., }}$ radiative, $\mathrm{Q}_{\text {rad. }}$,

562 evaporative, $Q_{\text {evap., }}$ and total, $\mathrm{Q}_{\text {total }}$ heat losses from the animal model to ambient air.

563

\begin{tabular}{|c|c|c|c|c|c|c|}
\hline \multirow{2}{*}{$\begin{array}{l}\text { Simulation } \\
\text { parameters }\end{array}$} & \multirow{2}{*}{$\begin{array}{l}\text { Simulation } \\
\text { values }\end{array}$} & \multirow{2}{*}{$\begin{array}{l}\text { Simulation } \\
\mathrm{T}_{\text {skin }}\left({ }^{0} \mathrm{C}\right) \\
\end{array}$} & \multicolumn{4}{|l|}{ Results } \\
\hline & & & $\mathrm{Q}_{\text {conv. }}(\mathrm{W})$ & Q ${ }_{\text {rad. }}(\mathrm{W})$ & $\mathrm{Q}_{\text {evap. }}(\mathrm{W})$ & $\mathrm{Q}_{\text {total }}(\mathrm{W})$ \\
\hline \multirow{3}{*}{$\mathrm{T}_{\mathrm{a}}\left({ }^{\mathrm{o}} \mathrm{C}\right)^{1}$} & 29.6 & 37.07 & 14 & 125 & 68 & 207 \\
\hline & 32 & 37.54 & 10 & 93 & 54 & 157 \\
\hline & 35 & 38.01 & 6 & 50 & 50 & 106 \\
\hline \multirow{3}{*}{$\mathrm{RH}(\%)^{2}$} & 57 & 37.07 & 14 & 125 & 68 & 207 \\
\hline & 70 & 37.15 & 14 & 126 & 58 & 198 \\
\hline & 80 & 37.21 & 14 & 127 & 51 & 192 \\
\hline \multirow{3}{*}{$\mathrm{v}_{\text {in }}(\mathrm{m} / \mathrm{s})^{3}$} & 0.04 & 37.07 & 14 & 125 & 68 & 207 \\
\hline & 0.5 & 35.91 & 42 & 106 & 184 & 332 \\
\hline & 1.0 & 35.64 & 46 & 101 & 213 & 360 \\
\hline \multirow{3}{*}{$\beta(\%)^{4}$} & 20 & 37.43 & 14 & 131 & 23 & 168 \\
\hline & 40 & 37.25 & 14 & 128 & 45 & 187 \\
\hline & 60 & 37.07 & 14 & 125 & 68 & 207 \\
\hline
\end{tabular}

$564 \quad{ }^{1}$ Fixed values: $\mathrm{RH}_{=} 57 \%, \beta=60 \%$, and $\mathrm{v}_{\mathrm{in}}=0.04 \mathrm{~m} / \mathrm{s} .{ }^{2}$ Fixed values: $\mathrm{T}_{\mathrm{a}}=29.6{ }^{0} \mathrm{C}, \beta=60 \%$, and $\mathrm{v}_{\text {in }}=$ $5650.04 \mathrm{~m} / \mathrm{s} .{ }^{3}$ Fixed values: $\mathrm{T}_{\mathrm{a}}=29.6{ }^{\circ} \mathrm{C}, \beta=60 \%$, and $\mathrm{RH}=57 \% .{ }^{4}$ Fixed values: $\mathrm{T}_{\mathrm{a}}=29.6{ }^{0} \mathrm{C}, \mathrm{v}_{\text {in }}=0.04$ $566 \mathrm{~m} / \mathrm{s}$, and $\mathrm{RH}=57 \%$.

567 